\title{
COMPARISON OF VARIOUS TYPES OF ILLUMINATION SCHEMES
}

\author{
MEGHANA MASUDI \& SAMAR A. M.
}

Department of Electrical Engineering, Reva Institute of Technology \& Management, Bangalore, India,

ABSTRACT
The reported research elaborates illumination schemes employed in the domestic applications. A unit of energy
saved is equivalent to three units of generation, hence it is also important to optimally utilize the available power rather than
increasing the generation capabilities. Illumination is of prime importance during off sunshine hours in industrial as well as
domestic applications; hence the need for energy efficient illumination systems has been exponentially increasing with
demand. Since the inception of the industrial revolution, the global energy consumption has increased exponentially to
fasten human living standard every day and to fulfill the needs of human living. So it gets very important for each of the
person living on this earth to save the mankind by not exploiting the non-renewable resources, rather making them a good
living by efficiently using the resources to make them last longer.
KEYWORDS: LED, CFL, Incandescent, Luminosity, Illumination \& Efficient Illumination

Received: Dec 05, 2018; Accepted: Dec 25, 2018; Published: Jan 14, 2019; Paper Id: IJEEERJUN20192

\section{INTRODUCTION}

Electrical lighting is a major part of global energy consumption. With day by day increase in electrical consumption and energy crisis, energy saving has become a need of the hour. The main objective of all the energy auditors have only been to try to save energy as much as possible by insisting consumers to use better illumination schemes like LED instead of Incandescent bulbs or sodium vapor lamps. Illumination systems need to be designed in a way that consumes an optimum amount of electrical energy. In this modern era, with the invention of LED lamps, which can produce better luminosity compared to the traditional lighting systems used ten years ago, while consuming half the electrical energy. The fast-growing world has to look forward to using energy efficient technologies due to a number of factors like cost in building new power plants and the continuous increasing difference between electricity demand and supply. The detailed study by J. Trifunovic has estimated a potential electrical energy savings of up to $27 \%$ in the residential sector and up to $30 \%$ in the commercial sector, making a huge difference in the global energy consumption. The current global electrical energy consumption per year is 109612.75TWh (2014). Out of which,15\%ofthetotalenergyconsumption, accounting to $16441.92 \mathrm{TWh}$ of electrical energy is used for the illumination. The industrial sector is the world's largest consumer of the electricity, hence having a larger scope to adopt energy saving schemes in illumination. Calculating the saving as per the study made by J. Trifunovic, even an average of $25 \%$ would account for a saving of at-least $4110.48 \mathrm{TWh}$ of energy.

\section{LITERATURE SURVEY}

The energy saving potential is possible with changing in illumination schemes. In the paper titled, "The Transition to Led Illumination" by Narendra B Soni, the author has discussed the varied forms of illumination schemes that were in use earlier and those that are in use currently by comparing the efficacy of all the different 
schemes of illumination. He rightly explains as to why using LED is a better illumination scheme than any other illumination scheme like Incandescent, Fluorescent, Sodium Vapor, Mercury Vapor etc. LED's have the highest efficacy when compared to Fluorescent and Incandescent illumination schemes as LED's have negligible driver losses and no production of heat. Hence, increasing the efficiency of LED's. He also compares the life span of a LED with that of an incandescent bulb. As per his study, LED has a lifespan of approximately 12 years and that of an in c and escent bulb it is just 3 months LED's do not even produces heat, thus not increasing a load of air conditioning, in turn, saving energy. After his study, he concludes that LED is better than any general illumination systems in terms of energy saving as well in terms of cost-effectiveness.

Lighting is the most important factor in any building. In the paper titled, Research Study on Gained Energy Efficiency in a Commercial Setup by Replacing Conventional Lights with Modern Energy Saving Lights by Ayesha Muneeb, the author has discussed the current scenario of energy crisis and blackouts, which is the biggest drawback in economic stability especially for the developing countries. In order to bridge the gap between the demand and supply of electrical energy, new illumination systems have been designed so as to increase the efficiency and conserve electrical energy. She has also discussed the interesting features that LED's currently have with high Color Rendering Index of greater than eighty, high luminous efficiency of about ninety to hundred lumens per watt, small size and a flexible, wide range of temperature of color and dynamic color control. She has also compared the output, estimated lifespan and maintenance cycles of LED's with traditional illumination systems. Has also compared the color rendering indices of varied illumination sources and concludes that the LED's are the technology of the future that has highly prompted for it

low energy consumption, high efficacy, and efficiency, long lifespan, high reliability, ease of use and high potential in conserving energy. Sources for generation of electricity are depleting at a rapid rate in the world. In the paper titled, Conservation of Energy by BiswajitBiswas, the author has claimed that to meet the energy crisis, end-user efficiency plays an important role. The author has discussed the energy consumption of India based on sectors. He claims that around fifteen thousand Megawatts of energy can be saved by following end-user energy efficiency. He has performed a case study on the replacement of existing lighting system i.e., fluorescent lamps, with that of LED's in the campus of an institutional area, claiming the payback period for it to be three years and four months. Thus, it is found that the improvement in the end-user efficiency with efficient LEDs provide significant result in conservation of energy. The operating life of the LED system is reasonably high which results in higher savings on initial investment on a long-term basis as compared to other lighting systems. Around $65 \%$ of annual energy consumption can be reduced by replacing all the traditional lighting systems with LED systems.

\section{METHODOLOGY}

The scope of this reported research includes evaluation of different illumination schemes. In the proposed methodology, a cube of the size of $1 \mathrm{~m} \mathrm{~L} \mathrm{x} 1 \mathrm{~m} \mathrm{~B} \mathrm{x} \mathrm{1m} \mathrm{H} \mathrm{is} \mathrm{built} \mathrm{using} \mathrm{a} \mathrm{plain} \mathrm{white} \mathrm{foam} \mathrm{board} \mathrm{to} \mathrm{eliminate} \mathrm{the} \mathrm{reflection} \mathrm{of} \mathrm{different} \mathrm{colors} \mathrm{as}$ shown in figure 1, and each of 5W LED Bulb, 5W CFL Bulb, and 5W Incandescent Bulb are bought and suspended into the cube from the top side in the middle of the cube on the top surface. By placing the lux meter at a distance of $0.25 \mathrm{~m}, 0.5 \mathrm{~m}$ and $1 \mathrm{~m}$ from the source of light of that particular illumination scheme, the illumination levels of all the three sources at all the three distances are measured, one at a time. The amount of energy consumption is based on the wattage consumed. 


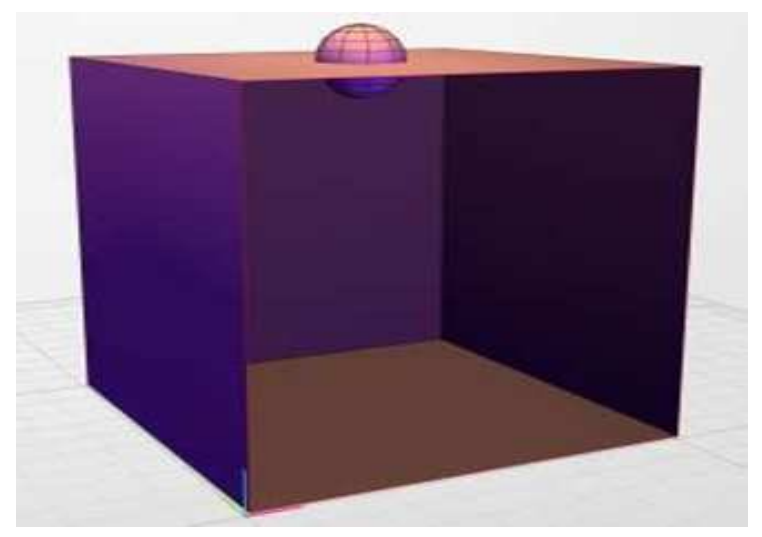

Figure 1: Cross Section of The 1sq. M Enclosed Cube

Luminous efficacy is a measure of how well a light source produces visible light. A ratio of luminous flux to power, measured in lumens per watt. We calculated the efficacy using the formula, Luminous Efficacy = Output of the illumination system in lumens / Input wattage to the illumination system.

Lux meter is a device used to measure luminous flux per unit area. A unit of lux is equal to one lumen per square meter area. This device measures the light intensity of an illumination system, irrespective of the type of illumination system used to measure. Light sources will appear dimmer as we move further from them because of the inverse square law. A light source

suffers from both the inverse law and absorption/scattering

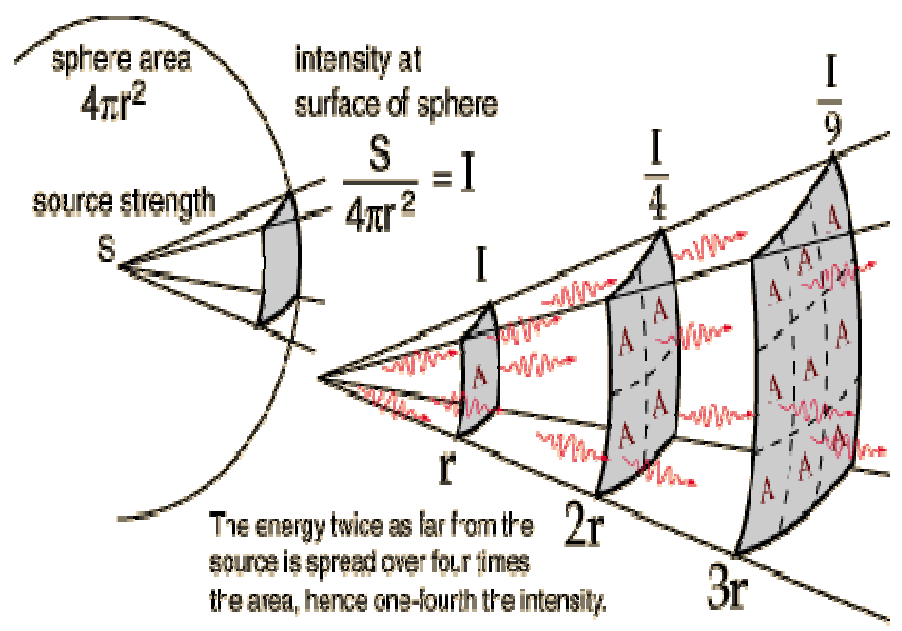

Figure 2: Change in Intensity at the Surface of a Sphere with a Change in Distance

As we move further away from the illumination source, the pupil represents a smaller area of the spherical shell representing the distance from the light source. This means we detect fewer photons from the illuminating source at a far distance. Also, the amount of area covered increases as the square of its distance.

Case Study 1: A case study of a room of the size $7.5 \mathrm{~m}$ x $5 \mathrm{~m}$ having 7 pairs of $25 \mathrm{~W}$ each Fluorescent tubes as shown in figure 2 with reflectors suspended from the ceiling at a distance 1 feet below the ceiling. Figure 3: Room with a placement of Fluorescent tubes 


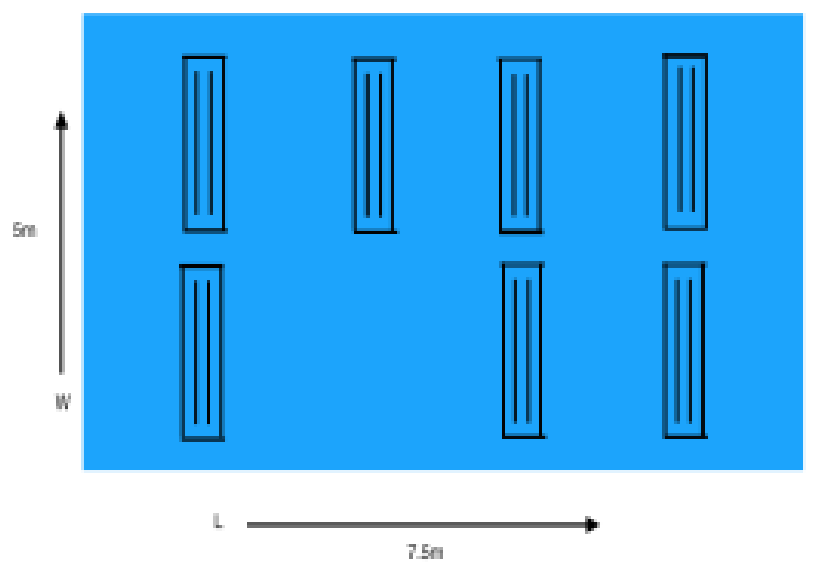

Figure 3: Room with a Placement of Fluorescent Tubes

The readings were taken at a distanceof 2.6mawayfrom the source of light perpendicular to the tubes dividing the whole space into 20 different points equidistant from each other.

Case Study 2: A case study of the same room with 3 numbers of 18W LED lamps placed as shown in Figure3 was performed to study the difference in illumination level between Fluorescent tubes and LED tubes.

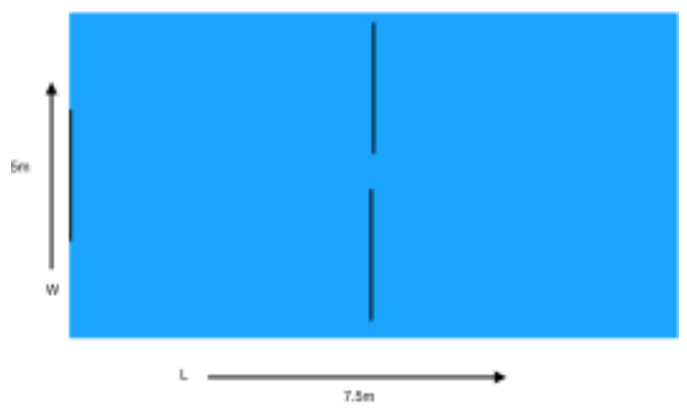

Figure 4: Room With A Placement of LED Tubes Result

\section{RESULTS}

Table 1: Lux Values with Different Luminaries

\begin{tabular}{|c|c|c|}
\hline $\begin{array}{l}\text { Type of lllumination } \\
\text { scheme }\end{array}$ & $\begin{array}{l}\text { Distance of Lux meter } \\
\text { from the seurce of light }\end{array}$ & Lua/sq.m \\
\hline \multirow{3}{*}{$\begin{array}{c}\text { Incandescent } \\
5 \mathrm{~W}\end{array}$} & $25 \mathrm{~cm}$ & 22 \\
\hline & $60 \mathrm{~cm}$ & 8 \\
\hline & $1000 \mathrm{~cm}$ & 3 \\
\hline \multirow{3}{*}{$\begin{array}{l}\text { CF } \\
\text { SW }\end{array}$} & $25 \mathrm{~cm}$ & 78 \\
\hline & $50 \mathrm{~cm}$ & 28 \\
\hline & $100 \mathrm{~cm}$ & 13 \\
\hline \multirow{3}{*}{$\begin{array}{l}\text { LED } \\
\text { SW }\end{array}$} & $28 \mathrm{~cm}$ & 672 \\
\hline & $60 \mathrm{~cm}$ & 227 \\
\hline & $100 \mathrm{~cm}$ & 79 \\
\hline
\end{tabular}

The luminosity levels of all three illumination schemes at different distances of $0.25 \mathrm{~m}, 0.50 \mathrm{~m}$, and $1 \mathrm{~m}$ are shown in Table 1. 


\section{DISCUSSION}

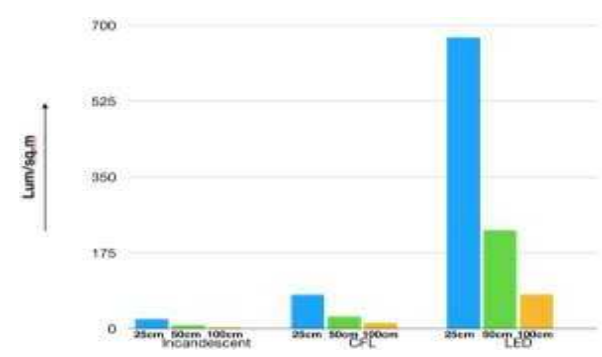

Figure 5: Comparison between Incandescent, CFL and LED In Terms Of LUX

From figure 4, it clearly shows that LED is way far better in terms of luminosity when compared to Incandescent and CFL and also at different distances from the source of light in lumens/sq. m.

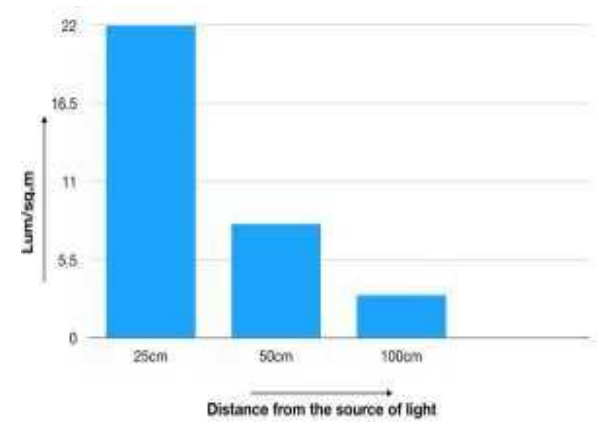

Figure 6: LUX at Different Distances With Incandescent

From figure 5, the graph explains the inverse square rule of distance from the source of light. As distance increases, the luminosity goes on decreasing by the square of the distance increased. The graph clearly shows the highest and the lowest luminosity level of an incandescent bulb of $5 \mathrm{~W}$. Even at just $0.25 \mathrm{~m}$, the luminosity is just $22 \mathrm{lum} / \mathrm{sq} . \mathrm{m}$ which is very less compared to the luminosity of CFL and LED.

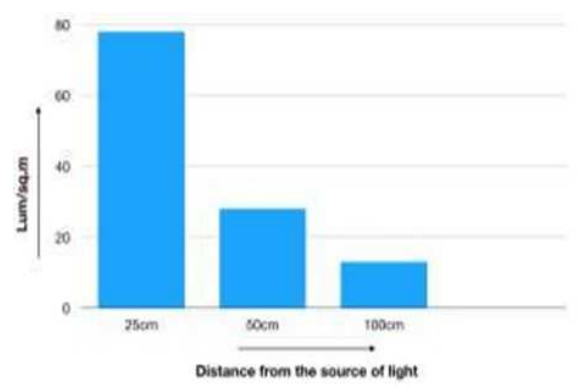

Figure 7: LUX t Different Distances With CFL

From figure 6, the graph shows the highest and the lowest possible lux levels of a $5 \mathrm{~W}$ CFL luminary at the distances of $0.25 \mathrm{~m}, 0.5 \mathrm{~m}$, and $1 \mathrm{~m}$ to measure the difference in the lux levels with distance. When compared with Incandescent and LED, CFL is the average between the both in terms of luminosity. 


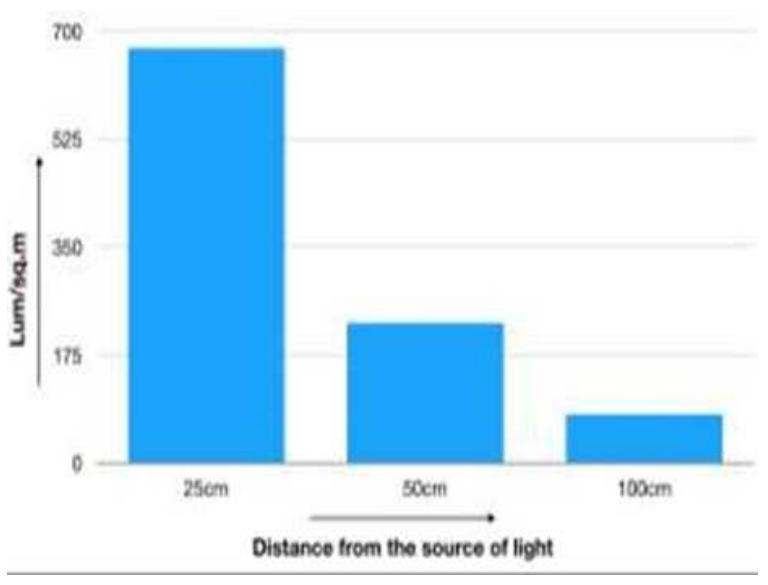

Figure 8: LUX at Different Distances with LED

From figure 7, it clearly shows that LED has the maximum luminosity at all three distances, and when figure 7 is compared to figure 5 and figure 6, it is clearly seen that LED is the best in terms of luminosity at all the three distances measured and the lumens values with a huge difference with the Incandescent and CFL.

\section{CONCLUSIONS}

Day by day the usage of electrical energy has been increasing exponentially by more than $100 \%$ globally due to the ever-increasing demand in developed and developing countries. One of the fastest options to save energy is to use energy efficient electrical appliances which save electricity using 3 star or 4 -star appliances, among which illumination system has great potential on saving electrical energy as $70 \%$ electricity is consumed by illumination itself. It has been observed that LED illumination is at least $30 \%$ better illumination scheme compared to CFL and Incandescent illumination schemes in terms of energy consumption as well as the output produced in lumens. From the results above, we can conclude that LED illumination scheme not only saves energy and money with a much higher life but also produces more brightness (luminosity) at a lesser wattage level when compared to both CFL and Incandescent and a payback period of about just 2 years(subject to the investment). The maintenance costs decrease by at least $30 \%$ to $40 \%$ because the life of all the new energy efficient light sources is 5 times more than the existing fixtures. Replacing the CFLs and Incandescent bulbs with LEDs will lead to a drastic reduction of electricity usage for lighting by around 25\%. The technology of LED is being improved day by day and will strive to save many generating stations in the world.

\section{REFERENCES}

1. Ayesha Muneeb, Samialjaz, Souman Khalid and Aftab Mughal "Research Study on Gained Energy Efficiency in a Commercial Setup by Replacing Conventional Lights with Modern Energy Saving Lights,” Journal of Architectural Engineering Technology.

2. Tim Whitaker “Factor Fiction-LEDs don' tproduce heat," LEDs Magazine, May 10,2005.

3. NARENDRA B SONI and P. DEVENDRA “The Transition to LED Illumination: A Case Study on Energy Conservation," Journal of Theoretical and Applied Information Technology.

4. Devi, A. S., \& Mahesh, V. (2013). Performance Evaluation of Illumination Normalization Techniques for Face Recognition. International journal of research in engineering \& technology (IJRET) ISSN, 2321-8843.

5. Biswajit Biswas, Sujoy Mukherjee and Aritra Ghosh “Conservation of Energy: A Case Study on Energy Conservation in 
Campus Lighting in an Institution," International Journal of Modern Engineering Research, Vol.3, Issue.4, Jul - Aug. 2013pp1939-1941.

6. Mrs. Landge Shubhangi Sudhir "LED Illumination: A Case Study on Energy Conservation," International Journal of Engineering Research and General Science Volume 4, Issue 2, March-April,2016.

7. “India: Energy - Efficient Street Lighting - Implementation and Financing Solutions”-Adocument by the World Bank.

8. G. S. B. Ganandran, T. M. I. Mahlia, Hwai Chyuan Ong, B. Rismanchi and W. T. Chong "Cost-Benefit. Analysis and Emission Reduction of Energy Efficient Lighting at the Universiti Tenaga Nasional," Scientific World Journal. 2014; $2014: 745894$.

9. J. Trifunovic, J. Mikulovic, Z. Djurisic, M. Djuric and M. Kostic. "Reductions in electricity consumption and power

10. Demand in case of the mass use of compact fluorescent lamps, "Energy 34 (2009)1355-1363. 
